Fanum

Sociológico
Forum Sociológico

Série II

$23 \mid 2013$

Número 23

\title{
TIC no ensino secundário: usos e mediações
}

Nuno de Almeida Alves, Pedro Abrantes, Carla F. Rodrigues e Paulo Coelho Dias

\section{OpenEdition}

Journals

Edição electrónica

URL: https://journals.openedition.org/sociologico/861

DOI: 10.4000/sociologico.861

ISSN: 2182-7427

\section{Editora}

CICS.NOVA - Centro Interdisciplinar de Ciências Sociais da Universidade Nova de Lisboa

Edição impressa

Data de publição: 1 novembro 2013

Paginação: 87-95

ISSN: 0872-8380

\section{Refêrencia eletrónica}

Nuno de Almeida Alves, Pedro Abrantes, Carla F. Rodrigues e Paulo Coelho Dias, «TIC no ensino secundário: usos e mediações», Forum Sociológico [Online], 23 | 2013, posto online no dia 01 janeiro 2014, consultado o 31 março 2022. URL: http://journals.openedition.org/sociologico/861 ; DOI: https://doi.org/10.4000/sociologico.861

Este documento foi criado de forma automática no dia 31 março 2022

(C) CICS.NOVA 


\section{TIC no ensino secundário: usos e mediações}

Nuno de Almeida Alves, Pedro Abrantes, Carla F. Rodrigues e Paulo Coelho Dias

\section{As tecnologias da informação e da comunicação na escola: políticas públicas, usos e benefícios}

1 O impulso à crescente integração das tecnologias da informação e da comunicação (TIC) na educação conheceu um significativo recrudescimento por ocasião da emergência e popularização da noção da Sociedade da Informação e do Conhecimento enquanto modelo ideal de reestruturação das sociedades contemporâneas. Esta narrativa acerca do desenvolvimento do futuro da sociedade, assente no modo de produção informacional baseado no conhecimento (Castells, 2000), estimulou o debate e a subsequente ação política e programática dos estados nacionais para a definição de políticas públicas destinadas à rápida adequação multidimensional à nova forma de organização social (Alves, 2004).

2 Este debate definiu, desde logo, a educação como um dos eixos estruturantes do novo modelo de sociedade. 0 primeiro dos argumentos foi o de que a reestruturação da economia e do emprego implicada nesta mudança desenhava um novo perfil de competências para o conjunto da mão de obra (Yang, 2012): a literacia informática imprescindível para todos e a formação graduada e pós-graduada especializada de segmentos específicos, dirigida à construção e manutenção das autoestradas da informação e da respetiva articulação com as empresas e instituições reticulares (Castells, 2000). O segundo argumento prendeu-se com a atualização tecnológica desta dimensão estruturante das sociedades contemporâneas: se as TIC foram paulatinamente estendendo a sua influência a todo e qualquer domínio de ação social, como compreender a sua tímida inserção na escola, instância fundamental da formação de competências e transmissão do conhecimento? 
3 Embora a inventariação dos potenciais benefícios da utilização dos computadores na educação tenha sido praticamente contemporânea da sua emergência inicial ou da expansão mercantil dos mesmos (Mayfield e Ali, 1996; Somekh, 2000; Wellington, 2005), foi sobretudo a sua associação à narrativa das sociedades da informação e do conhecimento que favoreceu o desenho de políticas públicas de integração massiva das TIC nos processos de ensino e aprendizagem (Selwyn, 2008; Nivala, 2009).

4 Esta revolução tecnológica nas escolas, entusiasticamente impulsionada pelos responsáveis nacionais pelas políticas educativas (Governos) e pelos principais operadores do mercado das TIC e das telecomunicações (Somekh, 2000; Pelgrum, 2001; Wellington, 2005; Bestall, 2006), foi, de certa forma, organizada à revelia dos gestores e reguladores (instituições centrais da administração educativa e conselhos consultivos) e dos atores (diretores de escolas, docentes e alunos) dos processos educativos. A integração das TIC nos curricula nacionais operou-se sobretudo pela noção da literacia informática, ou seja, da dotação dos recursos mínimos implicados na operação de um computador e na utilização da internet à saída da escolaridade obrigatória. Esta noção corresponde, assim, à prescrição das competências consideradas necessárias pela procura nos recursos humanos para a sociedade da informação e do conhecimento e não a um pensamento estruturado acerca do modo como as TIC devem ser integradas no ensino, correspondendo a um conjunto claramente definido de objetivos, necessidades e previsão de resultados (Wellington, 2005).

5 A integração da tecnologia nas escolas não foi, assim, acompanhada do debate necessário acerca do grau de mudança implicado no maciço incremento das TIC nas escolas: deve constituir apenas mais uma disciplina ou implicar uma profunda revisão do currículo e nos métodos de ensino e aprendizagem, revolucionando integralmente o modo como a escola funciona nos dias de hoje (Aviram e Talmi, 2005)?

6 A ausência desta clarificação fornece argumentos aos principais detratores da integração das TIC nos processos de ensino e aprendizagem: a sua ineficácia e improdutividade (geral ou por disciplina) na melhoria dos resultados escolares dos alunos (Peslak, 2005; Hikmet et al., 2008). Contudo, esta conclusão talvez seja demasiado apressada e resultante de um equívoco relativamente ao lugar das TIC na escola. Atendendo à especificidade desta tecnologia, a respetiva utilização em sala de aulas seria mais adaptável ao trabalho de projeto (individual ou colaborativo), enquadrado numa conceção mais construtivista da educação (Palak e Walls, 2009; Costa, 2004), centrada no aluno e não tanto numa orientação educativa de pendor tradicionalista, centrada na transmissão de conhecimentos por parte do professor à plateia de alunos, na respetiva assimilação por parte destes e posterior demonstração dos conhecimentos adquiridos na execução de um teste ou exame, culminando este processo na atribuição de uma classificação. Nesta última aceção do processo educativo, as TIC terão realmente pouco a oferecer além da literacia informática, constituindo até um obstáculo à melhoria quantitativa dos resultados escolares dos alunos (Zhao e Frank, 2003: 816).

7 A ausência de uma estratégia coerente de integração das TIC nas escolas propiciou também uma incipiente utilização média em sala de aulas, em claro contraste com os investimentos efetuados e as expetativas geradas (Cuban et al., 2001, Somekh, 2004). Este aparente paradoxo deve-se, no entender dos entusiastas do processo - governo e conglomerados TIC (Selwyn, 2008; Nivala, 2009) -, à reduzida eficácia da utilização das TIC pelos professores na sala de aulas, concentrada sobretudo nas tradicionais atividades de exposição e menos no trabalho conjunto com os seus alunos. Mais uma 
vez, esta é uma explicação apressada, sendo esta menor utilização das TIC em sala de aulas resultante de circunstâncias e processos afetos ao conjunto dos atores (escolas, professores e alunos) e não tanto decorrente da responsabilidade de apenas um.

8 Em Portugal, a progressiva introdução das TIC nas escolas e nos processos de ensino e aprendizagem foi objeto de diversos programas ao longo das últimas décadas: Minerva, Nónio Século XXI e Plano Tecnológico da Educação¹. A literatura disponível (Paiva, 2002; Costa, 2004; Costa e Viseu, 2007), embora anterior à execução deste último plano, revela dificuldades de implementação semelhantes às encontradas no plano internacional, ainda que se registem diferenças significativas: uma implementação dos recursos tecnológicos mais tardia, menos alargada e recursos humanos de apetência mais desigual à utilização das TIC no ensino.

\section{Desenho metodológico}

9 A implementação do Plano Tecnológico da Educação constituiu o mote para a execução do projeto de investigação "Learn-Tech: Tecnologias da Informação e da Comunicação e Aprendizagem" ${ }^{2}$, cujo objetivo fundamental foi conhecer e analisar o modo como se está a processar a apropriação das TIC por parte dos estabelecimentos do ensino secundário e respetivos atores, bem como a respetiva integração nos processos de ensino e aprendizagem.

10 Este projeto incluiu a observação de doze escolas durante o ano letivo de 2010/2011, situadas em diferentes regiões do país e nas quais os referidos processos de modernização física e tecnológica se encontravam em etapas distintas. Em cada escola, foi aplicado um questionário aos diretores, outro a uma amostra de professores e um terceiro a várias turmas de estudantes, assegurando a máxima diversidade dos cursos científico-humanísticos (e excluindo os cursos tecnológicos e profissionais). Desta forma, recolheram-se, codificaram-se e analisaram-se, através do programa SPSS 18, as respostas de 12 diretores, 324 professores e 2674 alunos. Como informação complementar para a redação deste artigo, foram ainda analisados os resultados das provas nacionais e os relatórios de avaliação externa das respetivas organizações escolares, no sentido de enquadrar os dados obtidos nas restantes dinâmicas organizacionais.

11 Entre as diversas questões sobre as quais se recolheu informação, para o tema em análise no presente artigo realçamos as perguntas relativas à intensidade $\mathrm{e}$ modalidades de utilização das TIC por parte dos professores, nas diferentes dimensões do trabalho docente, bem como a possibilidade de estabelecer correlações desses regimes de utilização com possíveis variáveis explicativas, como são a escola, o grupo etário, o sexo, a área disciplinar, os recursos disponíveis, as competências detidas, a orientação pedagógica e a cooperação entre colegas.

12 Na linha de estudos internacionais mencionados no ponto anterior, procurámos assim não apenas descrever a intensidade e modalidades de uso das TIC nas escolas secundárias portuguesas, mas também compreender fatores que explicam esses modos de apropriação, o que se afigura fundamental para o desenho de políticas mais eficazes e equitativas, neste domínio. 


\section{A utilização das TIC na sala de aula: intensidade, modalidades e perfis}

13 Um dos dados mais salientes deste inquérito resulta do facto de $90 \%$ dos professores declararem utilizar computadores, internet e quadros interativos na sala de aula, pelo menos ocasionalmente. No entanto, os dados relativos à frequência da utilização, por parte dos restantes docentes, deixam em evidência a diversidade dos regimes atuais de apropriação tecnológica no trabalho pedagógico: $16 \%$ utilizam esporadicamente as TIC (menos de $10 \%$ das aulas); $24 \%$ utilizam as TIC com pouca frequência (11 \% a $25 \%$ das aulas); $20 \%$ utilizam-nas moderadamente ( $26 \%$ a $50 \%$ das aulas), $17 \%$ com regularidade ( 51 a $75 \%$ das aulas); e $23 \%$ de forma sistemática (mais de $75 \%$ das aulas). Esta intensidade da utilização não apresenta correlações significativas com o sexo, nem como o grupo disciplinar (apesar de os valores registados entre as professoras e na área das humanidades serem ligeiramente inferiores), mas sim com a idade dos docentes: são sobretudo os docentes mais jovens, formados mais recentemente e, por isso, com menos anos de carreira que mais frequentemente usam estas tecnologias nas suas aulas. Resultados semelhantes haviam já sido obtidos em Paiva, 2002.

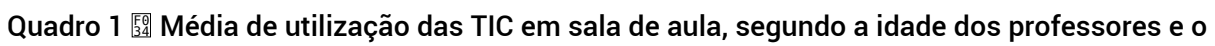
número de anos na carreira ${ }^{3},{ }^{4} \mathrm{e}^{5}$

\begin{tabular}{|c|c|c|c|c|c|}
\hline \multicolumn{3}{|c|}{ Escolso ctório" } & \multicolumn{3}{c|}{ Anos de correirs" } \\
\hline$<40$ & $40-50$ & $>50$ & $<15$ & $16-30$ & $>31$ \\
\hline 3,39 & 3,18 & 2,81 & 3,51 & 2,97 & 2,85 \\
\hline
\end{tabular}

Quanto às modalidades de utilização das TIC em sala de aula (ver Gráfico 1), os resultados do questionário aos docentes confirmam uma maior propensão da utilização das TIC em atividades rotineiras e não geradoras de uma inovação radical na modalidade de exercício da docência (Zhao e Frank, 2003). 


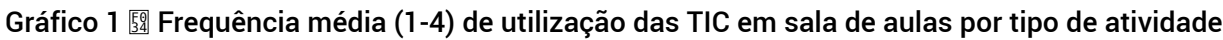

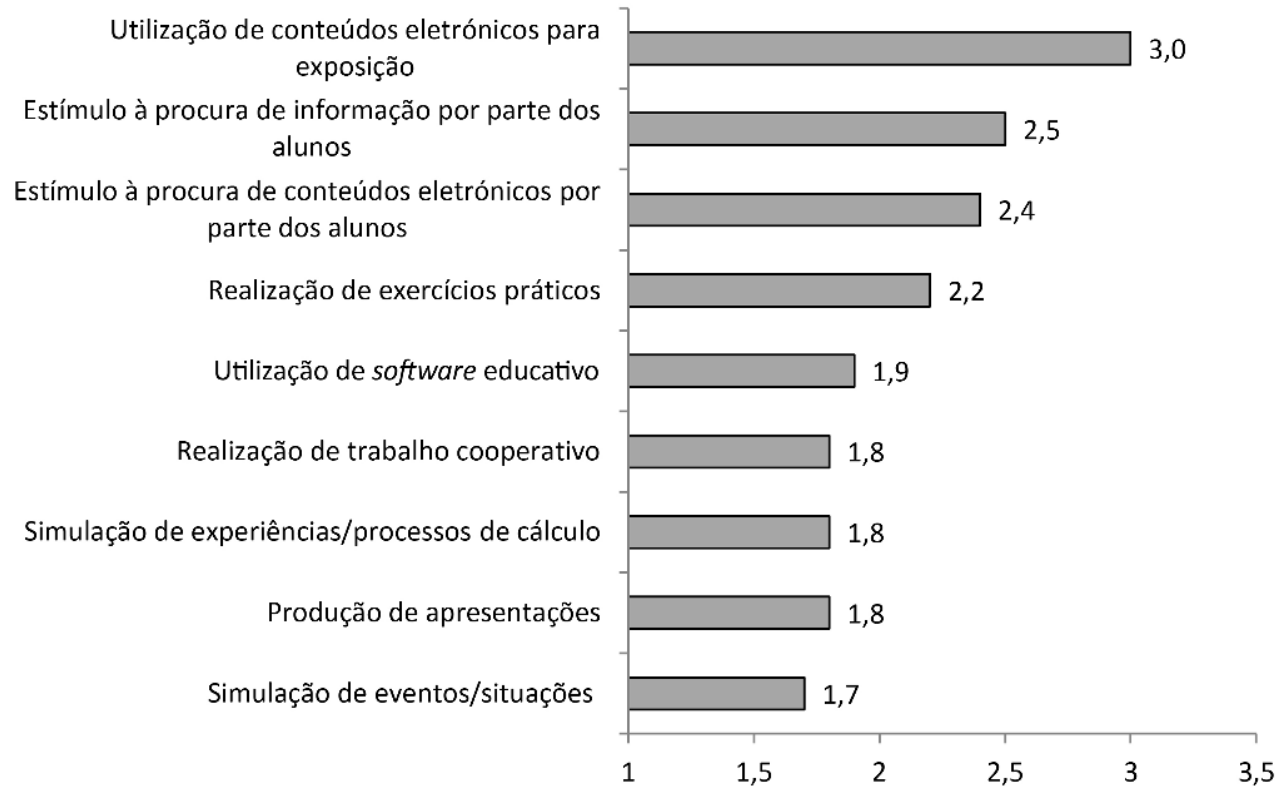

15 É sobretudo na exposição de conteúdos, substituindo parcialmente o uso anterior do quadro e/ou a projeção de "acetatos", que estas ferramentas são usadas, em contraste com a escassez do respetivo uso em apoio a atividades práticas realizadas pelos alunos (resolução de exercícios, utilização de software educativo, simulação de experiências e situações, produção de apresentações). É, aliás, significativo que a maior utilização dos meios informáticos por parte dos professores mais jovens se verifique, sobretudo, nesta modalidade de apoio à exposição, sendo que a utilização das TIC por parte dos alunos, em sala de aula, não varia de forma significativa entre os grupos etários. Num outro inquérito nacional aos professores de Matemática e de Ciências já tinha sido constatado que o modelo expositivo de aula continuava a ser dominante e que a correlação com a idade dos docentes não era significativa (Abrantes et al., 2008).

16 A partir da execução de uma análise de clusters $^{6}$ sobre estas modalidades de utilização das TIC em sala de aulas extraíram-se quatro perfis diferenciados entre os docentes: 0 perfil diversificado, menos numeroso $(\mathrm{N}=32)$ e que conjuga uma utilização muito alargada em quase todas as atividades elencadas, incluindo as mais raras; o perfil experimental ( $\mathrm{N}=39)$, caraterizado pela maior intensidade de utilização das TIC em exercícios práticos e na simulação de experiências, a par da exposição de conteúdos pedagógicos e utilização de software educativo; o perfil expositivo $(\mathrm{N}=46)$, que concentra a utilização das TIC na exposição de conteúdos, procura de informação e pesquisa de conteúdos eletrónicos; e finalmente, o perfil diminuto, o mais numeroso $(\mathrm{N}=82)$ e que agrupa o conjunto de professores que muito pouco frequentemente utiliza as TIC em qualquer uma destas atividades realizadas em sala de aula.

17 Do ponto de vista sociográfico, estes diferentes perfis de utilização das TIC em sala de aulas apresentam aspetos relevantes:

18 - Sexo: observa-se uma maior propensão para o perfil expositivo por parte das mulheres ( $25 \%$ contra $19 \%$ ) e para o perfil experimental por parte dos homens ( $28 \%$ contra 17 $\%)$; 
19 Idade: os perfis experimental (32\%) e expositivo (22\%) são mais frequentes entre os docentes com menos de 40 anos ( $32 \%$ e $22 \%$, respetivamente), enquanto o perfil diminuto é mais comum, tanto no escalão intermédio ( $40 \%$ ), como no escalão dos docentes com mais de 50 anos ( $52 \%$ ). O perfil diversificado é relativamente raro, não ultrapassando os $20 \%$ nos dois escalões etários mais jovens e $9 \%$ no mais idoso.

- Área disciplinar: entre os docentes de ciências exatas e naturais regista-se uma concentração natural no perfil experimental (45\%); em todos os outros perfis, assiste-se a um posicionamento modal no perfil diminuto, com destaque para as humanidades, onde é maioritário (57\%). Entre os docentes das ciências sociais e do comportamento é também significativo o contingente de docentes agrupados no perfil expositivo (31\%).

21 De referir, por fim, que embora nesta análise tenhamos aprofundado o caso da utilização das TIC no contexto da sala de aula, a sua frequência está correlacionada, de forma estatisticamente significativa, com o seu uso em outras dimensões do trabalho docente $^{7}$. Os resultados do questionário mostram que as TIC são utilizadas frequentemente, pela maioria dos docentes, para a preparação de aulas, o contacto com colegas e a gestão das turmas. Registando valores mais baixos, a utilização das TIC para a comunicação com os alunos é também comum, sendo no entanto muito menos frequente para a comunicação com os encarregados de educação ${ }^{8}$. Como seria de esperar, os docentes que utilizam as TIC regularmente nestas atividades são também aqueles que mais recorrem a elas no trabalho de sala de aula.

\section{Interpretações dos padrões observados: recursos, representações e competências}

A diversidade dos regimes de utilização das TIC na sala de aula pode ser interpretada à luz de três grandes grupos de fatores que condicionam e orientam o trabalho docente: os recursos, as representações e as competências.

Quanto aos recursos, podemos começar por constatar que quase todos os docentes dispõem de computador em casa (99 \%) e de ligação à internet (95\%), sendo que a larga maioria $(76 \%)$ utiliza diariamente a internet, nomeadamente, para enviar e receber correio eletrónico e para procurar informação, através de motores de busca. No entanto, no contexto escolar e de sala de aula, a situação é diferente. Se a larga maioria dos inquiridos conta hoje, na sala de aula, com um computador e um projetor, apenas $11 \%$ afirmam dispor de computadores para os alunos, encontrando-se as alternativas, como requisitar computadores portáteis $(21 \%)$ ou transferir a aula para um laboratório de informática (19\%), dependentes do planeamento prévio e da disponibilidade no horário da aula.

O questionário aos diretores confirmou este cenário de grande diversidade de recursos tecnológicos entre escolas. Embora longe da meta de um computador para cada dois estudantes, expressa no Plano Tecnológico para a Educação, foi possível observar um notável contraste entre sete escolas com um parque tecnológico significativo (um computador com ligação à internet para menos de 8 alunos, sendo que em duas delas este valor é apenas 4) e outras em que os meios informáticos são ainda escassos (um computador com acesso à rede para mais de 12 alunos). A esta diferença correspondem, obviamente, oportunidades desiguais de apropriação da tecnologia para o trabalho pedagógico.

Forum Sociológico, 23 | 2013 
25 Além disso, entender o próprio contexto organizacional enquanto recurso para a utilização das TIC no trabalho pedagógico implica considerar não apenas a tecnologia disponível na escola, mas também o modo como esta é gerida, dentro da organização, e, sobretudo, a capacidade da mesma para coordenar, apoiar e alargar a utilização das TIC para propósitos pedagógicos (por exemplo, através da manutenção dos equipamentos, a aquisição de software, a produção e administração local de aplicações, a formação do quadro docente, etc.). A este propósito, é significativo que o questionário aos docentes aponte para respostas muito diferenciadas, quanto à adequação dos equipamentos informáticos e da assistência técnica fornecida pela respetiva escola, enquanto se observa um maior consenso na discordância quanto à afirmação: “a escola dispõe dos materiais pedagógicos (conteúdos eletrónicos e software educativo) necessários à bemsucedida aplicação das TIC às minhas aulas" 9. Ainda assim, a diversidade entre escolas neste campo não é negligenciável. A análise deste conjunto de indicadores permitiu-nos chegar a uma tipologia de organizações escolares, curiosamente com quatro das doze escolas estudadas a enquadrarem-se em cada um dos perfis:

a) Escolas inovadoras: com recursos significativos, combinando soluções proprietárias e outras de software livre, adquirindo software educativo e aplicações locais, com direções e coordenações TIC comprometidas com a utilização das TIC no trabalho pedagógico.

b) Escolas tradicionais: com falta de recursos tecnológicos, utilizando apenas aplicações básicas da Microsoft e o Moodle, não existindo uma coordenação, nem uma estratégia efetivas para o reforço das TIC no ensino-aprendizagem;

c) Escolas ambivalentes: caraterizada por uma combinação pouco consistente de indicadores, provavelmente devido à existência de dinâmicas locais tanto de reforço da utilização da tecnologia, como de resistência a esta apropriação, gerando projetos inovadores, mas sem capacidade para protagonizar uma estratégia organizacional coerente (ver Quadro 2). 
Quadro 2 蛪 Recursos, estratégia e intensidade de uso das TIC, segundo a escola e a tipologia de escolas construída

\begin{tabular}{|c|c|c|c|c|c|c|}
\hline Tipologia & Cód. & $\begin{array}{l}\text { Alenol } \\
\text { comp. } \\
\text { intermet }\end{array}$ & $\begin{array}{c}\text { Frequêacia } \\
\text {-so el sula }\end{array}$ & $\begin{array}{l}\text { Frequêtucia } \\
\text { uso forma } \\
\text { de suls }\end{array}$ & $\begin{array}{c}\text { H.= de } \\
\text { serrigose } \\
\text { projetos } \\
\text { locais TIC }\end{array}$ & $\begin{array}{c}\text { Estratégia } \\
\text { TIC }\end{array}$ \\
\hline \multirow{4}{*}{$\begin{array}{l}\text { Escolas } \\
\text { Inovadoras }\end{array}$} & $\mathrm{A}$ & 4.4 & 3.23 & 2.70 & Elevado & Avançada \\
\hline & $J$ & 5.0 & 3.32 & 3.06 & Elevado & Média \\
\hline & K & 7.6 & 3.69 & 2.92 & Elevado & Média \\
\hline & L & 4.5 & 3.14 & 3.10 & Médio & Avançada \\
\hline \multirow{4}{*}{$\begin{array}{l}\text { Escolas } \\
\text { Tradicionais }\end{array}$} & c & 17.3 & 3.91 & 3.40 & Reduzido & Básica \\
\hline & D & 14.1 & 4.57 & 3.10 & Médio & Básica \\
\hline & E & 19.3 & 4.05 & 3.48 & Elevado & Média \\
\hline & 1 & 12.3 & 4.58 & 3.63 & Reduzido & Básica \\
\hline \multirow{4}{*}{$\begin{array}{l}\text { Escolas } \\
\text { ambíguas }\end{array}$} & $\mathrm{B}$ & 5.7 & 4.17 & 3.00 & Elevado & Média \\
\hline & $\mathrm{F}$ & 19.3 & 4.10 & 3.13 & Reduzido & Média \\
\hline & $\mathrm{G}$ & 7.5 & 3.97 & 3.01 & Elevado & Média \\
\hline & $\mathrm{H}$ & 4.2 & 3.99 & 3.02 & Elevado & Média \\
\hline
\end{tabular}

29 A análise em detalhe desta tipologia merece, por si própria, um artigo (Abrantes et al., 2013). Em todo o caso, podemos de forma sintética assinalar que os estudos internacionais sobre a apropriação das TIC no trabalho pedagógico tendem a atribuir um papel central ao contexto local e organizacional em que os docentes estão integrados (Zhao e Frank, 2003). Um relatório a partir de 17 inquéritos realizados na Europa mostrou que, em cada país, apenas uma minoria de escolas utilizou, até ao momento, as TIC para uma transformação efetiva do ensino-aprendizagem, enquanto a maioria das escolas se encontra ainda numa etapa inicial deste processo, utilizando as TIC de forma pouco continuada ou articulada, frequentemente, para reforçar metodologias pedagógicas mais tradicionais (Balanskat et al., 2006). Ainda que o carácter centralizado do sistema educativo português atribua, tradicionalmente, pouca margem para as escolas desenvolverem as suas próprias estratégias e práticas, este cenário tem vindo pouco a pouco a ser alterado. Embora as políticas de autonomia tenham efeitos relativamente mitigados (Barroso, 2006), áreas mais periféricas do currículo e em que a distribuição de recursos tem dependido também da iniciativa das escolas, como é o caso das TIC, contribuem para aumentar tais singularidades locais. Assim, estudos recentes têm identificado claramente diferentes "culturas de escola" (Torres, 2011). A este propósito, um estudo recente a partir de todos os relatórios de avaliação externa das escolas, através de uma análise fatorial, chegou a uma tipologia semelhante à que apresentamos aqui (Veloso et al., 2011).

30 Como seria de esperar, embora existam professores dos vários perfis em cada uma das escolas, a frequência média do uso das TIC em sala de aula é superior nas quatro "escolas inovadoras", sendo reduzida nas quatro "escolas tradicionais" e numa das "escolas ambivalentes". Mesmo numa pequena amostra de escolas como aquela com que trabalhámos, observam-se, pois, níveis de "e-maturidade" (Balanskat et al., 2006) muito assimétricos. 
31 No caso das representações dos docentes, referimo-nos especificamente às suas conceções sobre os benefícios (ou não) do uso das TIC no trabalho da sala de aula, bem como acerca da possibilidade e relevância da sua utilização, face aos currículos das disciplinas que lecionam. ${ }^{10}$

32 A este propósito, apesar da assinalável diversidade observada, a maioria dos docentes considera que as TIC aumentam o interesse dos alunos pelas aulas, enquanto apenas cerca de metade considera que a utilização das TIC produz vantagens, ao nível dos resultados académicos: a afirmação "Os alunos parecem mais atentos e interessados quando utilizo as TIC nas aulas" alcança um valor médio de 3,0, enquanto "Os alunos têm melhores resultados escolares quando utilizo as TIC nas aulas" regista um valor médio de 2,5. Como seria de esperar, os docentes mais céticos quanto aos benefícios das TIC são aqueles que raramente ou nunca as utilizam em sala de aula (perfil diminuto) ${ }^{11}$, enquanto as representações não parecem variar de forma significativa segundo os restantes três perfis anteriormente caracterizados (sendo ligeiramente inferiores, ainda assim, no perfil experimental).

Não deixa de ser revelador que as representações quanto aos benefícios das TIC não variem, de forma estatisticamente significativa, segundo o sexo ou o grupo etário dos docentes. No caso específico dos benefícios do uso das TIC nos resultados escolares dos alunos, é também de alguma forma surpreendente que sejam os docentes da área das ciências exatas e naturais que se destacam por respostas mais discordantes.

Por fim, no caso das competências, a metodologia do questionário é menos conclusiva, pois embora tenhamos inserido várias questões relativas ao tema, não devemos esquecer que estamos igualmente a tratar de representações dos docentes sobre si mesmos e que, no caso das respostas a um questionário, são influenciadas também por um "efeito de desejabilidade social", tanto mais que tratamos de um grupo profissional, cujas competências têm sido tão questionadas no debate público, em particular no âmbito da questão da avaliação de desempenho.

Em todo o caso, é revelador a este propósito que as respostas dos docentes tendam para a concordância com a afirmação: “em geral, os professores não dispõem de formação e de competências digitais suficientes para construírem, eles próprios, os conteúdos pedagógicos eletrónicos de que necessitam" (valor médio de 2,7). Quando indagados sobre as suas próprias competências, a larga maioria dos docentes (83 \%) declara não ter dificuldades no uso da internet, mas em relação à segurança na utilização do software, uma percentagem tão alta é apenas observada no caso do processador de texto, sendo que apenas uma minoria afirma utilizar sem problemas uma folha de cálculo e um pequeno segmento usa com segurança ferramentas de edição multimédia, redes sociais e edição HTML (ver Gráfico 2). 
Gráfico 2 [F⿻ software (\%)

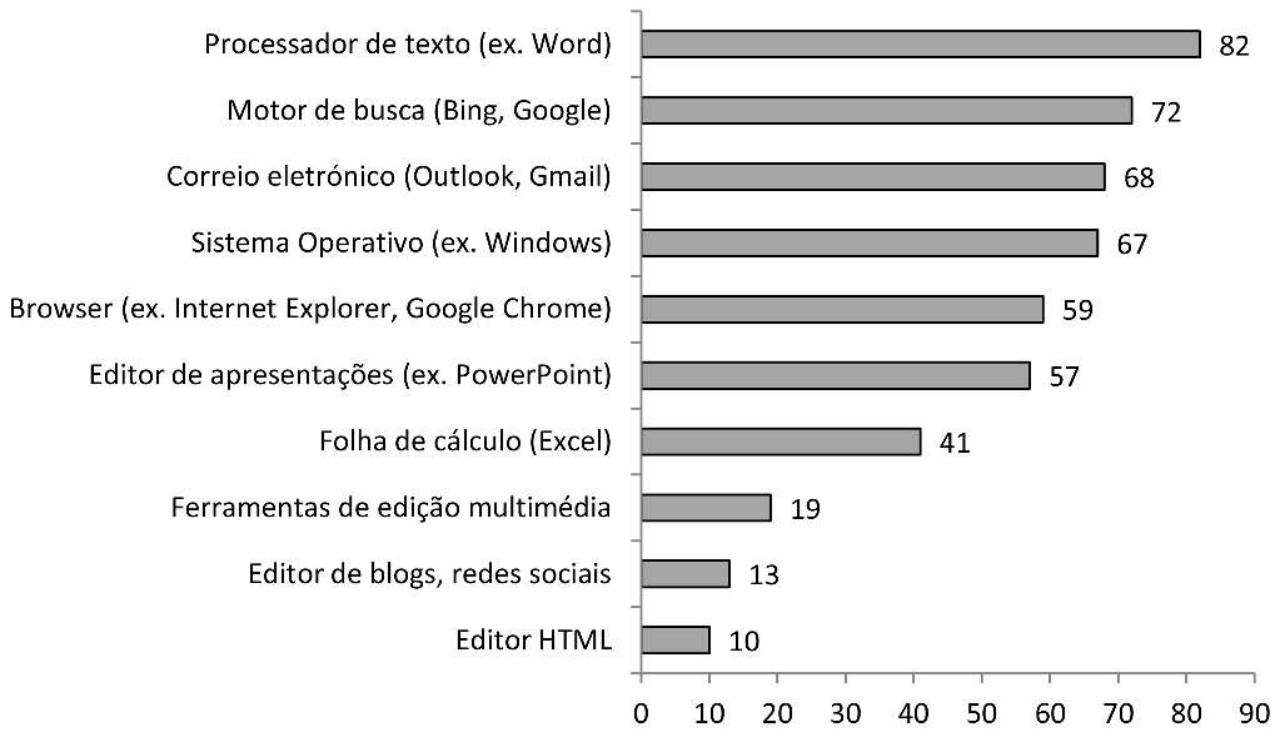

De notar que a segurança na manipulação do software, em particular quando esta é efetuada em ambiente de sala de aula, é, provavelmente, um dos elementos mais claramente limitativos de um alargamento de utilização das TIC nos processos de ensino-aprendizagem. A partir de uma análise de clusters $^{12}$ realizada sobre esta última variável, extraíram-se três perfis tipo de utilizadores: o elementar $(\mathrm{N}=78)$, que se sente confiante apenas na utilização das funções mais básicas; o intermédio $(\mathrm{N}=42)$, que declara um elevado grau de confiança no uso da maioria das aplicações (excetuando as de edição), e finalmente o perito ( $\mathrm{N}=81)$, que declara total confiança no uso de todas elas. Esta escala de competência técnica não só tem uma relação inversa com a idade ${ }^{13} \mathrm{e}$ número de anos de carreira ${ }^{14}$, privilegiando os mais novos, mas também incorpora uma correlação positiva com a frequência de utilização das TIC em sala de aulas ${ }^{15}$, tal como com os perfis de utilização em sala de aulas ${ }^{16}$. Os professores que se concentram no cluster com menores competências são os que menos recorrem às tecnologias em sala de aula (perfil diminuto) (64\%), os que detêm competências intermédias distribuem-se, essencialmente, entre o perfil expositivo (31 \%) e o perfil diminuto ( $29 \%$ ) e, como seria de esperar, a maioria dos professores que se enquadra num nível de competências mais elevado corresponde aos perfis experimental (35\%) e diversificado (29\%).

Em todo o caso, o que estes resultados sugerem é que, possuindo a generalidade dos docentes um acesso diário às TIC e utilizando-as efetivamente, destaca-se ainda um grupo de dimensão significativa com um tipo de utilização ainda bastante limitado a funções básicas e cujas competências e confiança dificultam a sua utilização com propósitos pedagógicos, em particular, no contexto da sala de aula. Este resultado está também associado à escassez de ações de formação de utilização pedagógica das TIC conjugada com a utilização destas ferramentas em sala de aula, para que os conhecimentos se sedimentem e tenham uma aplicabilidade direta e imediata, não correndo assim o risco de se desvanecerem. Neste âmbito, falta também conferir às escolas um pouco mais de protagonismo neste processo, inventariando recursos e capacidades formativas próprias por parte dos seus docentes para que pudessem auxiliar os colegas com mais dificuldades, transmitindo experiências didáticas de 
articulação entre as TIC e conteúdos disciplinares numa linguagem mais familiar e apreensível pelos colegas.

\section{Notas conclusivas}

38 Seja por opção do docente, por falta de equipamentos e aplicações ou pela forma como estes são geridos pela escola, o que os resultados deste projeto deixam em evidência é que as TIC, tal como noutros contextos nacionais, se encontram subutilizadas no ensino secundário regular, quer em termos de frequência de utilização em sala de aulas, quer das oportunidades pedagógicas que proporcionam (Cuban et al., 2001). Além disso, observa-se que a sua utilização tende a ocorrer no sentido de reforçar um modelo pedagógico eminentemente expositivo (Wellington, 2005), em detrimento tanto das orientações pedagógicas que salientam a importância de um ensino centrado no aluno como dos próprios modelos organizacionais "em rede", que habitualmente se associam à utilização das tecnologias nos diversos contextos sociais (Castells, 2000). E, se a utilização da tecnologia tende a alargar-se paulatinamente, em razão inversa à idade dos docentes, já a sua apropriação, enquanto reforço das atividades expositivas ou suporte de trabalho dos alunos, não varia de acordo com o escalão etários dos professores mas sobretudo com a intensidade das práticas de utilização quotidiana das TIC.

39 Apesar da propalada revolução tecnológica operada nas escolas, verifica-se que a qualidade e quantidade dos recursos TIC disponíveis em cada estabelecimento de ensino constituem ainda um fator relevante e diferenciador. 0 débito das redes locais e das ligações à internet, a quantidade e qualidade dos equipamentos informáticos e a disponibilidade de software adequado constituem ainda fatores explicativos dos usos efetuados nas escolas, suscitando mesmo situações de desigualdade de oportunidades entre o conjunto dos alunos de um mesmo sistema educativo. A cultura da organização escolar é também um fator influente, pelo maior ou menor impulso dado pela direção das escolas à utilização destes meios, tanto do ponto de vista da dotação de equipamentos como do estímulo à utilização pedagógica e didática das TIC por parte dos professores.

Entre os docentes a questão mais candente é a da carência de formação específica na utilização pedagógica das TIC. Parte significativa dos professores que hoje leciona nas escolas dos diversos segmentos de ensino não beneficiou de uma componente pedagógica da utilização das TIC no seu percurso formativo, tal como não a obteve no seu decurso profissional (Paiva, 2002; Costa e Viseu, 2007; Miranda, 2007). Desta forma, a generalidade dos professores opta por um regime de utilização das TIC em sala de aulas que em pouco ou nada muda a estratégia pedagógica seguida desde sempre (Somekh, 2004, Wellington, 2005): utilização de apresentações eletrónicas em detrimento das transparências analógicas; comunicação com os alunos por via eletrónica para a distribuição de apresentações eletrónicas ou resolução de dúvidas (Zhao e Frank, 2003). A utilização de outras estratégias pedagógicas menos conservadoras e mais centradas no aluno, no trabalho individual ou coletivo de pesquisa e de projeto são francamente mais raras (idem) e individualmente perseguidas por perfis determinados de docentes, com representações e atitudes mais afirmativas relativamente à utilização das TIC no ensino, tal como no respeitante às respetivas práticas de utilização na vida quotidiana. 
41 Neste sentido, o artigo põe em relevo a diversidade dos regimes de utilização das TIC em sala de aula, identificando alguns fatores relevantes para a frequência e as modalidades de uso. A existência de docentes - e de escolas - com um perfil de utilização das TIC ainda muito restrito deve constituir uma prioridade da intervenção, neste campo, no sentido de promover uma maior igualdade de oportunidades. Por seu lado, mesmo nos contextos em que existe já um parque informático significativo, continua a observar-se uma escassez de dispositivos organizacionais e ações de formação adequadas que permitam potenciar esses recursos para a melhoria dos processos de ensino e aprendizagem.

\section{BIBLIOGRAFIA}

ABRANTES, P. et al. (2008), Inquérito aos professores do 2.e e 3. ciclos de Matemática e de Ciências da Natureza (Relatório Final), Lisboa, Direção-Geral de Inovação e Desenvolvimento Curricular (DGIDC-ME).

ABRANTES, P. et al. (2013), "ICT in Portuguese secondary schools: from resistance to innovation", Revista de la Asociación Española de Sociología.

ALVES, N. de A. (2004), "Planos de acção para a sociedade da informação e do conhecimento: mudança tecnológica e ajustamento estrutural”, Sociologia Problemas e Práticas, 44, pp. 109-133.

ALVES, N. de A. et al. (2012), Learn-Tech: Tecnologias da Informação e Comunicação e Aprendizagem, Relatório Científico Final, CIES-IUL.

AVIRAM, A. e D. Talmi (2005), “The impact of Information and Communication Technology on Education: the missing discourse between three different paradigms", E-Learning, 2 (2), 169-191.

BALANSKAT, A. et al. (2006), The ICT Impact Report. A review of studies of ICT impact on schools in Europe, Bruxelas, European Commission/DG Education and Culture.

BARROSO, J. (2006), “A Autonomia das Escolas. Retórica, Instrumento e Modo de regulação da Acção Política”. In AAVV, A Autonomia das escolas, Lisboa, Fundação Calouste Gulbenkian, pp. 23-48.

BESTALL, L. (2006), "Enchanting a disenchanted world: revolutionizing the means of education using Information and Communication Technology and e-learning", British Journal of Sociology of Education, 27 (1), pp. 97-110.

CASTELLS, M. ([1996] 2000), The Information Age: Economy, Society and Culture, volume I: The Rise of the Network Society, Oxford, Blackwell Publishers.

COSTA, F. A. (2004), "O que justifica o fraco uso dos computadores na escola”, Polifonia, 7, pp. 19-32.

COSTA, F. e S. VISEU (2007), "Formação-Acção-Reflexão: um modelo de preparação de professores para a integração curricular das TIC", in F. A. Costa, H. Peralta e S. Viseu (orgs.), As TIC na Educação em Portugal. Concepções e Práticas, Porto, Porto Editora. 
CUBAN, L. et al. (2001), "High access and low use of technologies in High School classrooms: explaining an apparent paradox", American Education Research Journal, 38 (4), pp. 813-834.

HIKMET, N. et al. (2008), “The student productivity paradox: technology mediated learning in schools", Communications of the ACM, 51 (9), pp. 128-131.

MAYFIELD, J. e K. S. Ali (1996), "The internet as an educational tool”, Computers and Engineering, 31 (1 e 2), pp. 21-24.

MIRANDA, G. L. (2007), "Limites e Possibilidades das TIC na Educação”, Sísifo/Revista de Ciências da Educação, 3, pp. 41-50.

NIVALA, M. (2009), "Simple answers for complex problems: education and ICT in Finish information society strategies”, Media, Culture and Society, 31 (3), pp. 433-448.

PAIVA, J. (2002), As tecnologias de informação e comunicação: utilização pelos professores, Lisboa, ME/DAPP.

PALAK, D. e R. T. Walls (2009), “Teachers' Beliefs and Technology Practices: A Mixed-methods Approach", Journal of Research on Technology in Education, 41 (4), pp. 417-441.

PELGRUM, W. J. (2001), “Obstacles to the integration of ICT in education: results from a worldwide educational assessment”, Computers \& Education, 37, pp. 163-178.

PESLAK, A. R. (2005), “The Educational Productivity Paradox: studying the effects of increased ICT expenditures in educational institutions", Communications of the ACM, 48 (10), pp. 111-114. PRENSKY, M. (2001), “Digital Natives, Digital Immigrants”, On the Horizon, 9 (5), pp. 1-6.

SELWYN, N. (2008), "Realising the potential of new technology? Assessing the legacy of New Labour's ICT agenda 1997-2007”, Oxford Review of Education, 34 (6), 701-712.

SOMEKH, B. (2000), "New technology and learning: policy and practice in the UK, 1980-2010", Education and Information Technologies, 5 (1), pp. 19-37.

SOMEKH, B. (2004), “Taking the Sociological Imagination to School: an analysis of the (lack of) impact of information and communication technologies on education systems", Technology, Pedagogy and Education, 13 (2), pp. 163.180.

TORRES, L. L. (2011), “A construção de autonomia num contexto de dependências”, Educação, Sociedade \& Culturas, 32, pp. 91-109.

VELOSO, L. et al. (2011), “A avaliação externa de escolas como processo social”, Educação, Sociedade e Culturas, 33, pp. 69-88.

WELLINGTON, J. (2001), "Exploring the Secret Garden: the growing importance of ICT in the home", British Journal of Educational Technology, 32 (2), pp. 233-244.

WELLINGTON, J. (2005), "Has ICT come of age? Recurring debates on the role of ICT in education: 1982-2004”, Research in Science \& Technological Education, 23 (1), pp. 25-39.

YANG, H. (2012), “ICT in English Schools: transforming education?", Technology, Pedagogy and Education, 21 (1), pp. 101-118.

ZHAO, Y. e K. A. Frank (2003), “Factors Affecting Technology Uses in Schools: An Ecological Perspective", American Education Research Journal, 40 (4), pp. 807-840. 


\section{NOTAS}

1. Em parte também associado à execução do "Plano de renovação do parque escolar destinado ao ensino secundário" (http://www.parque-escolar.pt/pt/programa/programa-demodernizacao.aspx), pela necessidade de reabilitação da infraestrutura física prévia à instalação da tecnologia.

2. Financiado pela Fundação para a Ciência e a Tecnologia (Ref. PTDC/CS-SOC/102690/2008), coordenado por Nuno de Almeida Alves e desenvolvido no Centro de Investigação e Estudos de Sociologia, Instituto Universitário de Lisboa (CIES-IUL).

3. Os valores variam entre 1 (utilização em menos de $10 \%$ das aulas) e 5 (utilização em mais de $75 \%$ das aulas).

4. $f(2,294)=4,023 ; p=0,019$.

5. $f(2,294)=4,519 ; p=0,012$.

6. Realizado a partir de um K-means cluster, a partir do número de clusters sugerido por um cluster hierárquico (método vizinho mais afastado, intervalo do quadrado de distâncias euclideanas), $\mathrm{N}=$ 195. O procedimento efetuado eliminou um grande conjunto de docentes da análise (125) por não terem respondido a uma ou mais questões deste conjunto, ficando assim impossibilitados de se agruparem num dos perfis extraídos.

7. Pesquisa de informação para a preparação das aulas: $f(3,190)=13,015 ; p<0,001 /$ Frequência da preparação de conteúdos pedagógicos eletrónicos: $\mathrm{f}(3,190)=18,330 ; \mathrm{p}<0,001 /$ Frequência da comunicação com os alunos: $\mathrm{f}(3,190)=11,390 ; \mathrm{p}<0,001$.

8. Numa escala de 1 (nunca) a 4 (muito frequente), os valores médios obtidos para o uso das TIC nas primeiras atividades mencionadas situam-se entre 3,0 e 3,4, enquanto a comunicação com os alunos alcança 2,6 e a comunicação com os encarregados de educação apenas 1,9.

9. Numa escala de 1 (discordo totalmente) a 4 (concordo totalmente), o grau de concordância médio dos docentes em relação a esta afirmação foi de 2,1, sendo de 2,5 relativamente às outras duas afirmações: "A escola não dispõe de assistência técnica necessária a uma boa integração das TIC no processo de ensino e aprendizagem das minhas aulas" e "a escola tem o número de computadores adequados à bem-sucedida integração das TIC nas minhas aulas”. Estes valores variam pouco, considerando o sexo, o escalão etário ou o perfil de utilização das TIC.

10. Todos os valores médios abaixo indicados se referem a uma escala entre 1 (discordo totalmente) e 4 (concordo totalmente).

11. $\mathrm{f}(3,129)=5,49 ; p=0,001$.

12. À semelhança do procedimento estatístico realizado para identificar perfis diferenciados de utilização das TIC em sala de aula, realizou-se uma análise de Clusters (K-means cluster), $\mathrm{n}=205$.

13. $X^{2}(4)=21,542 ; p<0,001$.

14. $X^{2}(4)=2,535 ; p=0,002$.

15. $\mathrm{X}^{2}(8)=27,247 ; p=0,001$.

16. $X^{2}(6)=22,981 ; p=0,001$.

\section{RESUMOS}

A conceção do futuro das sociedades contemporâneas como sociedades da informação e do conhecimento trouxe uma revolução tecnológica às escolas. No entanto, a disseminação da tecnologia não obteve ainda correspondência no plano dos usos das TIC em sala de aulas, nos 
processos de ensino e aprendizagem no ensino secundário. Com base num inquérito realizado a 324 professores de 12 escolas disseminadas pelo país verificamos como as TIC são ainda incipientemente utilizadas nas salas de aulas, reforçando uma abordagem conservadora do ensino. Esta tendência central encerra, no entanto, uma grande diversidade de situações, de acordo com as diferenças entre os recursos tecnológicos nas escolas e com as representações e competências dos docentes.

The conception of the future of contemporary societies as information and knowledge societies has brought a technological revolution to schools. However, the dissemination of technology has not yet matched ICT use in the classroom, in the teaching and learning processes. Based on a survey of 324 teachers in 12 schools scattered throughout the country we observe that ICT are still incipiently used in the classrooms, reinforcing a traditional and conservative approach to teaching. This central tendency encompasses, however, a wide variation, according to differences found between schools' technological resources and in representations and competences of the teachers.

\section{ÍNDICE}

Keywords: secondary education, information and communication technologies, teaching, learning

Palavras-chave: ensino secundário, tecnologias da informação e da comunicação, ensino, aprendizagem

\section{AUTORES}

\section{NUNO DE ALMEIDA ALVES}

Professor Auxiliar, Instituto Universitário de Lisboa (ISCTE-IUL); Investigador, Centro de Investigação e Estudos de Sociologia (CIES-IUL) (nalmeidaalves@iscte.pt)

\section{PEDRO ABRANTES}

Investigador, Centro de Investigação e Estudos de Sociologia (CIES-IUL) (pedro.abrantes@iscte.pt)

\section{CARLA F. RODRIGUES}

Investigadora, Centro de Investigação e Estudos de Sociologia (CIES-IUL)

(carla.rodrigues@iscte.pt)

\section{PAULO COELHO DIAS}

Professor Adjunto, Escola Superior de Educação - Instituto Politécnico de Santarém, Investigador, Centro de Investigação e Estudos de Sociologia (CIES-IUL) (pgdias@sapo.pt) 